\title{
Investigação sobre as visões de um grupo de professoras acerca do uso das tecnologias em sala de aula para ensino de matemática: um olhar para a formação das pedagogas e as formas de utilização da tecnologia em seu fazer docente
}

\author{
Mariana Braun Aguiar - Universidade Federal do Rio Grande do Sul \\ mariana_braun94@hotmail.com \\ Marcus Vinicius de Azevedo Basso - Universidade Federal do Rio Grande do Sul \\ mbasso@ufrgs.br
}

Resumo: O presente artigo tem por objetivo identificar e compreender os impactos de uma suposta lacuna na formação de professores dos anos iniciais no que tange o uso das Tecnologias da Informação e Comunicação (TIC) para fins pedagógicos, em particular, no ensino de matemática. Para tanto, busca-se analisar os dados de um questionário aplicado a um grupo a 20 professoras das redes públicas das cidades de Canoas, Porto Alegre e Gravataí. Para análise dos dados coletados neste questionário, são utilizadas, principalmente, as ideias de Coll e Monereo (2010) acerca do ensino-aprendizagem na era tecnológica, bem como as de Rabardel (1995) sobre a gênese instrumental do professor. Os resultados apontam uma carência na abordagem das TIC na formação base do professor de anos iniciais, identificada tanto na análise de diferentes currículos de cursos referência de Pedagogia no país quanto nas respostas das professoras pesquisadas. Além disso, os dados produzidos indicam que os efeitos desta carência de abordagem do tema podem impactar em propostas de uso que não exploram de forma significativa as diversas potencialidades das TIC.

Palavras-chave: Tecnologias digitais; Educação Matemática; Professores dos anos iniciais.

\begin{abstract}
This article aims to identify and understand the impacts of an alleged gap in the formation of teachers of the initial years regarding the use of information and communication technologies (ICT) for pedagogical purposes, in particular, in the teaching of Math. To this end, it seeks to analyze the data of a questionnaire applied to a group of 20 teachers from public networks in the cities of Canoas, Porto Alegre and Gravataí. To analyze the data collected in this questionnaire, it is mainly used the ideas of Coll and Monereo (2010) about the teaching-learning in the technological era, as well as those of Rabardel (1995) on the instrumental genesis of the teacher. The results indicate a lack of the approach of ICT in the basic formation of the teacher of early years, identified both in the analysis of different curricula of pedagogy reference courses in the country and in the answers of the teachers surveyed. Moreover, the data produced indicate that the effects of this lack of approach to the theme may impact on proposals for use that do not significantly exploit the various potential of ICT.
\end{abstract}

Keywords: Digital technologies; Mathematical Education; Elementary school teacher.

\section{Introdução}

Atualmente, por consequência do aumento do uso da tecnologia em diversas áreas do conhecimento e para realização das mais variadas tarefas, o uso das TIC para aprendizagem escolar é uma tendência que vem se instalando gradualmente no cenário educacional. Com isso, surgem demandas relacionadas à formação docente e às estruturas das instituições educacionais. (Coll e Monereo, 2010; Gómez, 2015) 
Ao decidir realizar uma pesquisa sobre as visões dos pedagogos acerca da inserção das TIC em sala de aula, com um olhar voltado aos aspectos da formação e aos diferentes usos dados aos recursos tecnológicos por tais pedagogos, em particular para ensino de matemática, os autores da pesquisa partiram de uma suposição: a de que a formação básica do pedagogo ainda não aborda de forma significativa a inclusão das TIC no fazer docente. Para analisar a procedência desta hipótese inicial, foram pesquisados os currículos do curso de Pedagogia nas 10 universidades ${ }^{1}$ melhores avaliadas no mais recente IGC - Índice Geral de Cursos disponível (divulgado em 2016), um indicador que avalia as instituições de ensino superior no Brasil, cujo o cálculo é de responsabilidade do Ministério da Educação. As informações coletadas nos sites das respectivas universidades são sistematizadas no quadro a seguir.

Quadro 1: Disciplinas voltadas ao uso das TIC no currículo dos cursos de Pedagogia nas 10 universidades melhores avaliadas no IGC mais recente.

\begin{tabular}{|c|c|c|}
\hline Universidade & $\begin{array}{l}\text { Disciplinas voltadas às } \\
\text { TIC no currículo do curso } \\
\text { de Pedagogia }\end{array}$ & $\begin{array}{l}\text { Número de créditos (cada } \\
\text { crédito configura carga horária } \\
\text { de } 15 \text { horas) }\end{array}$ \\
\hline $\begin{array}{l}\text { Universidade Federal do } \\
\text { Mato Grosso (UFMT) }\end{array}$ & Tecnologias da Educação & 4 (obrigatórios) \\
\hline $\begin{array}{l}\text { Universidade de Brasília } \\
\text { (UNB) }\end{array}$ & $\begin{array}{l}\text { Ensino de Ciência e } \\
\text { Tecnologia }\end{array}$ & 3 (obrigatórios) \\
\hline $\begin{array}{l}\text { Universidade Federal do } \\
\text { Piauí (UFAM) }\end{array}$ & $\begin{array}{l}\text { Informática aplicada à } \\
\text { Educação (disciplina de } \\
\text { caráter optativo) }\end{array}$ & 4 (optativos) \\
\hline $\begin{array}{l}\text { Universidade Federal de } \\
\text { Ouro Preto (UFOP) }\end{array}$ & - & - \\
\hline $\begin{array}{c}\text { Universidade Federal de São } \\
\text { Carlos (UFSCAR) }\end{array}$ & - & - \\
\hline $\begin{array}{l}\text { Universidade Federal de } \\
\text { Viçosa (UFV) }\end{array}$ & Tecnologias na Educação & 4 (obrigatórios) \\
\hline $\begin{array}{l}\text { Universidade Estadual de } \\
\text { Londrina (UEL) }\end{array}$ & - & - \\
\hline $\begin{array}{c}\text { Pontifícia Universidade } \\
\text { Católica do Paraná (PUCPR) }\end{array}$ & - & - \\
\hline $\begin{array}{l}\text { Universidade Católica de } \\
\text { Pernambuco (UNICAP) }\end{array}$ & - & - \\
\hline $\begin{array}{c}\text { Universidade Federal do Rio } \\
\text { Grande (FURG) }\end{array}$ & - & - \\
\hline
\end{tabular}

Fonte: os autores.

Além da pesquisa nos cursos referência no país, foram analisados os currículos das principais universidades que oferecem o curso de Pedagogia nas cidades em que se localizam as escolas das professoras pesquisadas. Nestes currículos, os dados encontrados também de aproximam daqueles percebidos anteriormente.

\footnotetext{
${ }^{1}$ Dentre as 10 Universidades presentes na tabela abaixo, estaria a Universidade Federal do Sergipe. No entanto, o currículo da graduação em Pedagogia não estava disponível no momento da pesquisa no site da Universidade (16/5/2018 às $14 \mathrm{~h})$
} 
Quadro 2: Disciplinas voltadas ao uso das TIC no currículo dos cursos de Pedagogia nas principais Universidades das cidades em que se localizam as escolas das professoras pesquisadas.

\begin{tabular}{|c|c|c|}
\hline Universidade & $\begin{array}{l}\text { Disciplinas voltadas às } \\
\text { TIC no currículo do curso } \\
\text { de Pedagogia }\end{array}$ & $\begin{array}{l}\text { Número de créditos (cada } \\
\text { crédito configura carga horária } \\
\text { de } 15 \text { horas) }\end{array}$ \\
\hline $\begin{array}{c}\text { Universidade La Salle - } \\
\text { Canoas }\end{array}$ & $\begin{array}{c}\text { Informática e Multimeios } \\
\text { na Educação; Tecnologias } \\
\text { na Educação }\end{array}$ & 8 (obrigatórios) \\
\hline $\begin{array}{l}\text { Universidade Federal do Rio } \\
\text { Grande do Sul (UFRGS) - } \\
\text { Porto Alegre }\end{array}$ & $\begin{array}{c}\text { Mídias, tecnologias } \\
\text { digitais e educação: } \\
\text { processos e métodos de } \\
\text { aprendizagem; } \\
\text { Computador na Educação } \\
\text { (disciplina de caráter } \\
\text { optativo) }\end{array}$ & 6 (3 obrigatórios e 3 optativos) \\
\hline $\begin{array}{c}\text { Universidade Luterana do } \\
\text { Brasil (ULBRA) - Gravataí e } \\
\text { Canoas }\end{array}$ & $\begin{array}{c}\text { Tecnologias da } \\
\text { informação e da } \\
\text { comunicação na educação }\end{array}$ & 4 (obrigatórios) \\
\hline $\begin{array}{c}\text { UniRitter - Porto Alegre e } \\
\text { Canoas }\end{array}$ & $\begin{array}{c}\text { Tecnologias da } \\
\text { informação e da } \\
\text { comunicacão na educacão }\end{array}$ & 4 (obrigatórios) \\
\hline
\end{tabular}

Fonte: os autores.

A partir da pouca ou nenhuma carga horária dispendida no currículo destes cursos para tratar especificamente sobre o uso das TIC, pode-se perceber que, de forma geral, há indicativos de que a formação básica do pedagogo, o profissional que é habilitado, dentre outras funções, à docência na educação infantil e anos iniciais, aborda pouco ou não aborda o tema. Desta forma, pode-se supor também que a inserção das TIC em sala de aula somente ocorrerá se houver um movimento de busca, por parte do professorado, de formação continuada nesta área.

Sendo assim, torna-se relevante a pesquisa com o pedagogo que já atua em sala de aula para mensurar os possíveis efeitos desta lacuna que os currículos em pedagogia apresentam, bem como identificar os diferentes usos que os mesmos dão às TIC em suas salas de aula. Devido ao fato de ambos os autores deste artigo serem pesquisadores da área do ensino de matemática, aproveita-se este questionário para incluir questões voltadas ao uso das TIC especificamente para ensino da matemática, na busca de explorar possíveis continuidades desta pesquisa com ênfase maior neste aspecto.

Neste artigo, a organização se dá da seguinte forma: na seção 1 , o tema é introduzido e justificado; na seção 2, é apresentado o referencial teórico utilizado para análise dos dados produzidos; na seção 3, é descrito o questionário respondido pelos participantes da pesquisa; na seção 4, são apresentadas as perguntas do questionário, seguidas da descrição das respostas obtidas e respectivas análises e, por fim, a seção 5 aborda as considerações finais.

\section{Referencial Teórico}

Coll e Monereo (2010) abordam questões relacionadas à educação na era digital que se constituem importantes para discussão neste artigo. A principal delas que julgamos importante abordar é relacionada aos contextos de uso das TIC em sala de aula e a capacidade efetiva desses recursos para causar mudanças nas dinâmicas de sala de aula, tanto no que tange tanto o trabalho do professor quanto a aprendizagem do estudante. 
O que ocorre é que se trata de um potencial que pode ou não vir a ser uma realidade, e pode tornar-se uma realidade em maior ou menor medida, em função do contexto no qual as TIC serão, de fato, utilizadas. São, portanto, os contextos de uso [...] que acabam determinando seu maior ou menor impacto nas práticas educacionais e sua maior ou menor capacidade para transformar o ensino e melhorar a aprendizagem. (Coll e Monereo, 2010, p. 66 e 67)

Na obra destes mesmos autores, são descritas diversas pesquisas realizadas em escolas de países ibero-americanos, as quais lhes permitem concluir que, na maioria dos casos, o uso das tecnologias tem se mostrado pouco inovador e não tem trazido grande diferencial quando comparado às metodologias de ensino que não utilizam as TIC. Desta forma, Coll e Monereo (2010, p. 74 e 75) destacam que a incorporação destes recursos de forma limitada à fonte de acesso à informação, ou como ambiente de repetição daquilo que pode ser proposto, sem perdas, sem o uso das TIC, não explora os potenciais existentes nestes recursos.

A novidade, em resumo, está realmente no fato de que as TIC digitais permitem criar ambientes que integram os sistemas semióticos conhecidos e ampliam até limites inimagináveis da capacidade humana e (re)apresentar, processar, transmitir e compartilhar grandes quantidades de informação com cada vez menos limitações de espaço, de tempo, de forma quase instantânea e com um custo econômico cada vez menor (Coll e Monereo, 2010, p. 76)

Dessa forma, fica evidente a importância de que a formação base dos professores aborde, além de investigações de diferentes ferramentas que envolvam as TIC e formas de utilização da mesma em sua prática docente, questões relacionadas a outros dois aspectos: a justificativa de utilização de um determinado recurso tecnológico, isto é, o motivo pelo qual o uso da tecnologia é determinante para a realização de determinado estudo ou tarefa e a definição dos objetivos para os quais servem o recurso em um dado contexto.

No que se refere mais especificamente ao tema formação de professores, o principal autor a embasar teoricamente este artigo é Rabardel (1995) e suas ideias relacionadas à Gênese Instrumental.

Inicialmente, se faz necessário definir dois conceitos básicos desta teoria, que são os de artefato e instrumento. Segundo Rabardel (1995), artefato é um objeto material ou simbólico entre si, e Instrumento, seria uma entidade mista, formada pelo artefato e os esquemas de utilização do mesmo para determinadas tarefas. Gênese Instrumental seria um processo evolutivo e complexo que se estabelece no contato e manipulação de um artefato por parte de um sujeito, processo este que gera o instrumento.

A Gênese Instrumental, portanto, se dá na familiarização, utilização e manipulação das diferentes ferramentas presentes no artefato. Neste sentido, Rabardel (1995) diferencia o processo de reconhecimento das potencialidades e diferentes ferramentas presentes do artefato, chamando-o de instrumentalização, do processo de elaboração dos diferentes esquemas de utilização deste artefato, chamando-o de instrumentação. 

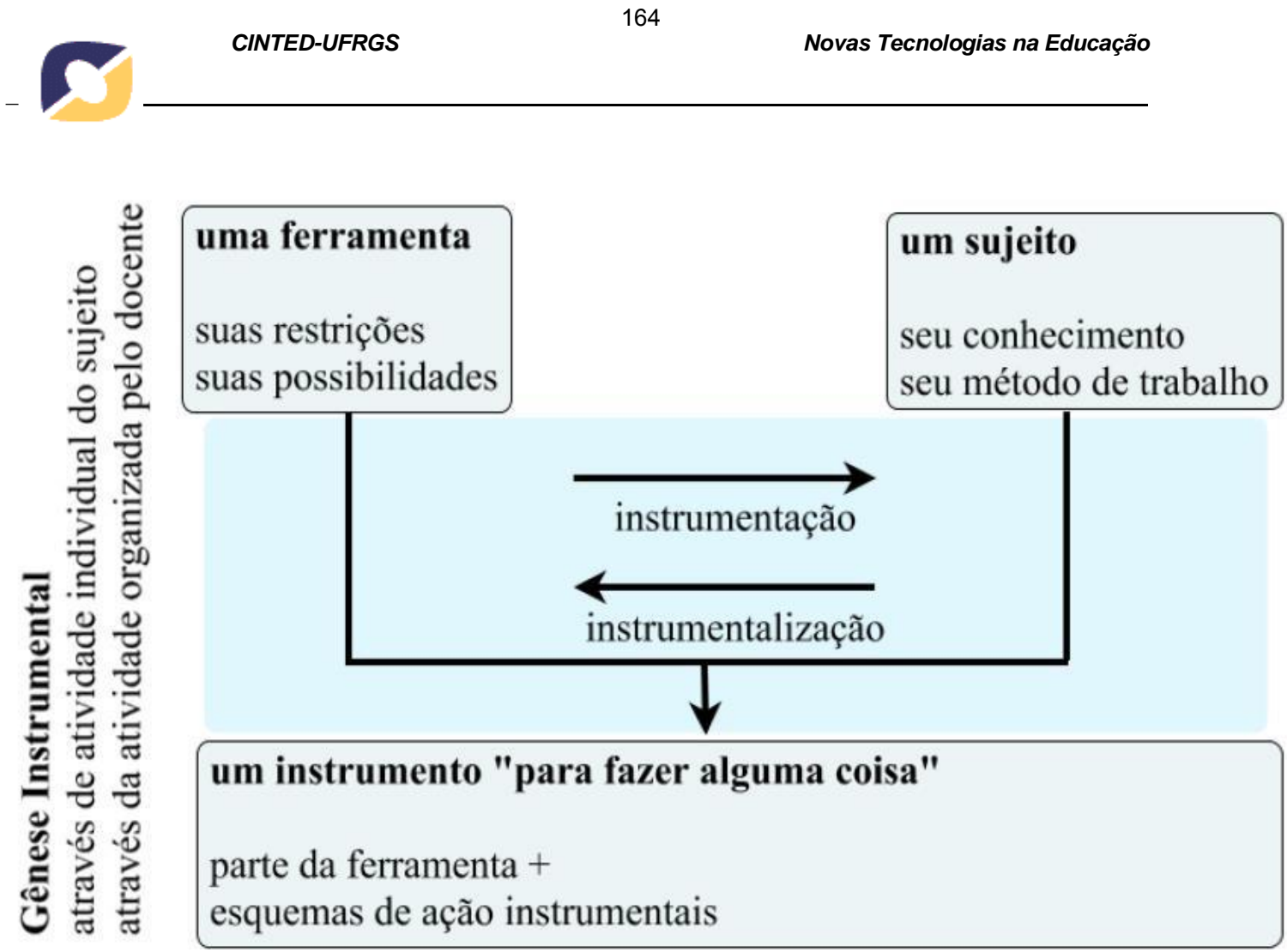

Figura 1 - Esquema conceitual sobre a Gênese Instrumental Fonte: Notare e Basso (2017), traduzido de Trouche (2004)

No processo de instrumentalização, o artefato determina a relação com o sujeito, ditando os limites de atuação daquele artefato ao realizar determinadas tarefas. Após este processo, o sujeito passar a dominar a relação com o artefato, no processo de instrumentação, no qual o sujeito faz uso do artefato, através de esquemas de utilização, já conhecendo suas potencialidades e limitações.

Relacionando este processo com a atuação de um professor em sala de aula através da tecnologia, podemos perceber este movimento de troca entre artefato e sujeito: o professor se apropria do recurso tecnológico proposto, suas potencialidades e limitações, explorando técnicas e testando esquemas de utilização (instrumentalização) e, após, este processo possibilita novos métodos de atuação em sala de aula e, mais amplamente, influencia em sua formação profissional (instrumentação). Neste sentido, ao analisar o uso da tecnologia por parte de um professor, deve-se observar dois aspectos: a apropriação do artefato tecnológico por parte do sujeito e desenvolvimento de um instrumento, denominada Gênese Pessoal, e o processo de integração deste instrumento em seu fazer docente, denominado Gênese Profissional. (Haspekian, 2013)

\section{Materiais e Métodos}

Um questionário físico com 8 perguntas a serem respondidas de forma dissertativa foi entregue a 20 professoras, de forma aleatória e a partir da demonstração do interesse em participação por parte das professoras, em 4 instituições públicas de ensino fundamental de diferentes cidades da região metropolitana de Porto Alegre/RS. Justificamos a escolha por estas 4 instituições específicas salientando que as mesmas foram as escolas de atuação de um dos um dos autores deste artigo em sua trajetória até o momento, o que facilitou o acesso às mesmas. Além disso, em estudos futuros sobre o tema, tem-se o objetivo de atuar nestas mesmas escolas, por isso a importância deste estudo investigativo inicial ser realizado nestas realidades escolares.

As perguntas elencadas no questionário, além daquelas relativas à idade, formação 
e instituição(ões) de atuação, convidam o professor a posicionar-se diante das questões da inserção da tecnologia no meio educacional, explanando sua utilização pessoal e profissional dos artefatos tecnológicos, os aspectos que tangem a sua formação para o uso da tecnologia em sala de aula, bem como as condições ligadas à infraestrutura apresentadas pelos seus ambientes de trabalho para tal. Além disso, há perguntas ligadas especificamente ao uso da TIC para ensino de matemática, devido à relação do tema às pesquisas atuais dos autores. As perguntas são apresentadas na próxima seção, juntamente com a descrição e análise das respostas coletadas.

\section{Análise dos Dados Produzidos}

Foram recebidos 17 questionários respondidos por professoras atuantes em 3 cidades diferentes da região metropolitana do Porto Alegre (2 escolas da rede municipal de Canoas, 2 escolas da rede municipal de Gravataí, 1 escola da rede estadual de Gravataí e 1 escola da rede municipal de Porto Alegre). As professoras possuem idade entre 25 e 61 anos, todas com formação mínima de graduação em pedagogia, atuantes há pelos menos 3 anos nas suas respectivas redes de ensino. Neste grupo pesquisado, 16 professoras possuíam pelo menos um curso de pós-graduação lato sensu, mas nenhuma destas especializações era na área de utilização das TIC. Nesta seção, as perguntas aparecem destacas do texto em quadros e, a seguir, seguem descrição e análise das respostas recebidas.

Questão 1) "No que tange o uso de tecnologias em sala de aula como ferramenta que pode auxiliar na aprendizagem dos alunos, o professor pode se posicionar de diferentes formas. Pode ser favorável ao uso e atuar em uma instituição que apresenta infraestrutura para tal, o que possibilita a inserção da tecnologia em sua metodologia com os alunos; pode ser favorável ao uso, mas a inserção se tornar impossibilitada devido à falta de estrutura de sua instituição ou pode discordar que o uso da tecnologia possa trazer benefícios na aprendizagem dos estudantes. Como você se posiciona em relação a esta situação?"

Todas as professoras que responderam se mostraram favoráveis ao uso das tecnologias, embora apontem diversas dificuldades de utilização em sala de aula em função da falta de estrutura das escolas em que atuam. Isto indica que a posição desse grupo de professoras reconhece a importância da incorporação das TIC nas escolas, o que, segundo Coll e Monereo (2010), realmente não costuma ser questionado pela maioria dos docentes.

[...] os argumentos a favor da incorporação das TIC na educação formal e escolar passam a ser, na verdade e com muita frequência, um axioma que não se discute ou que encontra sua justificativa última nas facilidades que essas tecnologias oferecem para implementar certas metodologias de ensino ou certos postulados pedagógicos previamente estabelecidos e definidos em suas linhas essenciais. (Coll e Monereo, 2010, p.69)

Questão 2) Em sua formação, houve algum momento em que você teve contato com o uso de tecnologias digitais (uso de softwares, objetos virtuais ou qualquer outro recurso utilizado através de computadores, tablets, celular, etc) para fins pedagógicos? Se sim, descreva brevemente o(s) contexto (s) em que ocorreu.

Os questionários coletados indicaram que 4 das 17 professoras responderam que não houve nenhum momento de contato, 2 responderam que houve um contato que consideraram insuficiente e 11 responderam que houve contato satisfatório para sua 
formação, mas descreveram este contato com tecnologia em momentos de realização de tarefas próprias, apresentações de trabalho nas disciplinas da graduação, estabelecer comunicação com colegas e pesquisar conteúdos. Desta forma, se pode perceber que o contato com tecnologia destas professoras em sua formação não alcançou o patamar de utilização das TIC como ferramenta para ensino em suas salas de aula, sobre o qual se referia a pergunta.

Coll e Monereo (2010, p. 118) destacam que "o que o professorado deve aprender a dominar e a valorizar não é só um novo instrumento, ou um novo sistema de representação do conhecimento, mas uma nova cultura de aprendizagem". Sendo assim, as respostas obtidas com este grupo de professoras mostram que esta nova cultura de aprendizagem a qual o autor se refere não foi incorporada durante sua formação como uma ferramenta para exploração do aluno, guiado pela proposta de uso elaborada pelo professor, e sim como um instrumento facilitador de outras tarefas docentes.

Questão 3) Em sua formação, houve algum momento em que você teve contato com o uso de tecnologias digitais (uso de softwares, objetos virtuais ou qualquer outro recurso utilizado através de computadores, tablets, celular, etc) para ensino de matemática? Se sim, descreva brevemente o(s) contexto (s) em que ocorreu

Em relação à questão anterior, as respostas coletadas mostraram que a unanimidade de professoras consultadas não teve nenhuma formação prévia para o ensino de conceitos matemáticos via tecnologia. Desta forma, nota-se que momentos exploradores dos processos de instrumentalização (Rabardel, 1995), em que o professor se apropria de recursos tecnológicos dados, não foram possibilitados, pelo menos nas vivências de sua formação base de professora.

Questão 4) Você já utilizou tecnologia em sala de aula com seus alunos? Se sim, descreva o recurso tecnológico utilizado e a finalidade do uso.

Questão 5) Você já utilizou tecnologia em sala de aula com seus alunos para ensinar matemática? Se sim, descreva o recurso tecnológico utilizado e a finalidade do uso

Nas respostas à questão 4, a unanimidade das professoras consultadas relatou já ter feito uso de tecnologia com seus alunos, e as finalidades mais citadas foram: para trabalho com jogos, como fonte de pesquisa, para utilização de projeção de imagens e vídeos. Apenas uma professora abordou ter feitos usos diferenciados destes, como a utilização de blogs para postagem de atividade e acompanhamento das aulas e uso de softwares voltados a alunos de inclusão.

Já nas respostas à questão 5, as professoras responderam que já utilizaram e todas elas descreveram o uso baseado em jogos e pesquisa de desafios de lógica. As demais, responderam jamais ter utilizado.

Nas respostas obtidas para as questões 4 e 5, observa-se que o uso das tecnologias digitais, quando ocorre, acontece de forma superficial, explorando pouco daquilo que as mesmas podem oferecer. Coll e Monereo destacam:

[...] o tipo de mente virtual que a incorporação das TIC em nossa cultura vai gerar dependerá de que em nossa sociedade se promova não só um uso pragmático dessas TIC, o que inegavelmente é imprescindível, mas também um uso epistêmico. Em suma, será preciso que nossos alunos pensem "com" as TIC e, 
além disso, que pensem "nelas" como um sistema para transformar a mente e tornar possível outros mundos em nossa mente. (Coll e Monereo, 2010, p.107)

Dessa forma, é possível identificar, mesmo na formação daquelas professoras que tiveram contato com as TIC em sua formação, uma lacuna no que se refere às formas de maximizar o uso das potencialidades das TIC. O uso como ferramenta única de pesquisa, seja de dados, imagens ou vídeos, determina uma certa escassez de profundidade nas pesquisas no momento em que assume tudo aquilo que se encontra na web como sendo verdadeiro e inquestionável. $\mathrm{O}$ uso exclusivo como banco de dados não explora as caraterísticas de dinamismo, utilização de diferentes recursos gráficos que se pode encontrar em diversas ferramentas, assim como também não explora a questão do domínio dos diferentes sistemas de linguagem utilizados em cada ferramenta de TIC.

Coll e Monereo (2010, p. 118 e 119) destacam que o uso das TIC em sala de aula tem potencial para fomentar uma nova cultura de aprendizagem pautada em características exigidas pela sociedade atual. Dentre elas, temos o desenvolvimento da habilidade de organizar a atribuir significado à quantidade de informação que as TIC podem oferecer e o aprendizado relativo à construção de um senso crítico e questionador. O que se pode notar na forma como as professoras descrevem o uso da tecnologia em suas salas de aula, é que este potencial não tem sido totalmente explorado, ficando o uso da tecnologia com caráter mais voltado ao aspecto lúdico ou como material de consulta.

Questão 6) Você acredita que o uso de tecnologias digitais pode trazer avanços na aprendizagem de matemática? Se sim, de que forma? Se não, por qual motivo?

Em relação à questão 6, as professoras entrevistadas responderam que acreditam que o uso das tecnologias pode trazer avanços na aprendizagem de matemática. A maioria dos aspectos citados como diferenciais que a tecnologia traz consigo foram: o dinamismo, a possibilidade de construção de interações/conexões entre diferentes conteúdos e o fato de ser algo que, segundo as professoras, "chama a atenção dos estudantes".

Nesse sentido, é de conhecimento da maioria das professoras participantes do estudo que, assim como defendem Coll e Monereo (2010, p. 110), a "pluralidade representacional e o uso integrado de múltiplos códigos tornam possível um conhecimento integrado e multimídia que parece ser o suporte ideal para o pensamento complexo". Desta forma, fica evidente que, neste grupo de professoras, as potencialidades do uso das TIC são percebidas, embora não colocadas em prática por motivos relacionados à estrutura e às lacunas na formação das mesmas.

Questão 7) Que uso você faz das tecnologias no seu fazer diário, seja fora ou dentro da sala de aula?

Nas respostas à esta questão, as professoras questionadas relataram que utilizam tecnologia em seu fazer diário pessoal, para finalidades de lazer, comunicação e atualização. Isso mostra que a cultura tecnológica faz parte da vida das professoras participantes do projeto em diversos âmbitos. No entanto, apenas 5 delas relataram fazer uso no âmbito profissional de forma direcionada à aprendizagem dos estudantes, incluindo planejamento e execução de atividades pedagógicas. Este dado mostra que, em sua maioria, as professoras entrevistadas concebem a tecnologia como facilitador de diversas atividades pessoais em seu cotidiano, mas ainda não tiveram acesso a momentos de integração da tecnologia para atuação pedagógica. 
No que tange a aproximação destas professoras às diferentes ferramentas digitais para aprendizagem dos estudantes, podemos identificar dois momentos importantes que apresentam relação de dependência: em um primeiro momento, é necessário que as professoras se apropriem de diferentes recursos tecnológicos, suas potencialidades e limitações, explorando técnicas e testando formas de utilização; após, então, este processo teria potencial para possibilitar novos métodos de atuação em sala de aula e, mais amplamente, influenciar em sua formação profissional. No entanto, as respostas das professoras mostram que não lhes foram possibilitados momentos de exploração de ferramentas tecnológicas voltadas à aprendizagem, o que impossibilita que as professoras a integrem em seu fazer docente. Deste modo, fica justificado o tipo de uso das TIC que as professoras relatam fazer em suas salas de aula: uma utilização que não explora a maioria das múltiplas potencialidades existentes nas TIC.

Analisando este dado a partir dos termos definidos por Rabardel (1995), é possível supor que não foram propiciadas situações em que as professoras, em sua formação, manipulassem artefatos tecnológicos que lhes permitissem a vivência do processo de gênese instrumental, que seria estabeleceria no contato e manipulação de um artefato e estabelecimento de esquemas de utilização deste artefato para fins pedagógicos.

Questão 8) Você acredita que sua formação de professor (a) de anos iniciais lhe preparou para inserir a demanda tecnológica em sua metodologia de ensino?

Nas respostas à última questão do instrumento de pesquisa, 15 das 17 professoras relataram não terem sido preparadas para utilização da tecnologia em sala de aula e 2 consideram que sua formação abordou satisfatoriamente o trabalho com a tecnologia nas escolas. É importante destacar a resposta de duas professoras, que responderam não terem sido preparadas especificamente para a utilização da tecnologia em seu fazer docente, mas que sua formação evidenciou a importância de o professor estar sempre em movimento no sentido de atualizar suas práticas, trazendo a responsabilidade de se apropriar da tecnologia como possiblidade para a sala de aula como sendo do professor, assim que ele detecta esta demanda.

\section{Considerações Finais}

A partir da análise realizada na seção anterior, é possível destacar dois aspectos evidenciados por esta pesquisa: primeiramente, a lacuna na formação de professores para uso das TIC, que já havia sido sugerida pela análise dos currículos realizadas na seção 1, confirmou-se no conjunto de professoras participantes da pesquisa e, em segundo lugar, é reforçada a hipótese de que esta pouca ou nenhuma capacitação obtida em sua formação inicial impacta na forma de uso das TIC nas salas de aula destas professoras.

Em geral, notou-se que a maioria das docentes pesquisadas, embora utilize as TIC, faz um uso que costuma ficar limitado às facilidades trazidas pela tecnologia para comunicação, pesquisa, projeção de imagens e vídeos e proposição de jogos on-line, o que praticamente não explora os potenciais de integração de sistemas semióticos, conforme aborda Coll e Monereo (2010, p.76). Não foi objetivo desta pesquisa julgar a validade o uso das TIC pelas professoras de ano iniciais, mas sim identificar os efeitos destas lacunas de formação na forma de uso desses recursos tecnológicos, além de compreender a forma como as professoras questionadas enxergam essa demanda em suas escolas.

A partir do conjunto de respostas recebido, ficou destacado o quanto o professorado é dependente de formação prévia qualificada - o que é de se esperar - para utilização de uma nova ferramenta em sua sala de aula. Sendo assim, é utópico esperar que as TIC 
sejam utilizadas com profundidade em propostas pedagógicas por professoras que relatam não se considerarem capazes para tal.

Como também mostra a observação dos currículos de Pedagogia de diferentes Universidades mencionada na seção 1 , se faz necessária uma reformulação curricular na formação base do professor de anos iniciais: a graduação em Pedagogia. Em uma reformulação em que o uso das TIC ganhe espaço no currículo, os pedagogos, já em sua formação inicial, teriam vivenciado situações de um uso significativo das TIC em sala de aula e, portanto, se sentiriam capacitados para a inserção das mesmas como um recurso importante e que, por sua vez, constitui um meio para uma aprendizagem pautada nas exigências da sociedade atual.

Além disso, para os professores que já exercem a profissão, se fazem necessárias iniciativas de formação continuada, para que os docentes já aptos a atuar nas escolas se sintam capacitados para um uso significativo das TIC em seu fazer docente.

Gómez (2015) destaca a necessidade de um repensar bastante profundo sobre as funções da escola na era digital, defendendo que a inclusão das TIC não é suficiente para resolver os problemas atuais da educação. "Essa mudança de perspectiva não faz referência a transformações superficiais, mas a replanejamentos radicais que afetam o sentido e a revisão dos próprios objetivos da escola". (Gómez, 2015, p. 45)

Desta forma, a lacuna identificada na formação das professoras pesquisadas se mostra como sendo apenas um dos diversos aspectos a serem repensados no modelo de escola atual, mas que, se revisto, poderia contribuir para o processo de aprendizagem dos alunos da atualidade.

\section{Referências}

COLL, C.; MONEREO, C. Psicologia da educação virtual - Aprender e Ensinar com as Tecnologias da Informação e da Comunicação. Porto Alegre: Artmed, 2010

GOMÉZ, A. Educação na Era Digital: A Escola Educativa. Porto Alegre: Artmed, 2015.

HASPEKIAN, M. Enseigner avec un tableur: quelles genèses instrumentales? In: Les technologies numériques pour lénseignement: usages, dispositifs et genèses. Toulouse: OCTARÈS Editions, 2013

NOTARE, M; BASSO, M. Gênese Instrumental do Geogebra na Formação de Professores. Zetetiké. Campinas, SP, v.25, n.2, 2017, p.324-344.

RABARDEL, P. Les hommes et les technologies: une approche cognitive des instruments contemporains. Paris: Armand Colin, 1995

TROUCHE, L. Managing the complexity os human/machine interactions in computerized learning environment: guiding student's command process through instrumental orchestrations. International Journal of Computers for Mathematical Learning. Netherlands, 2004. 